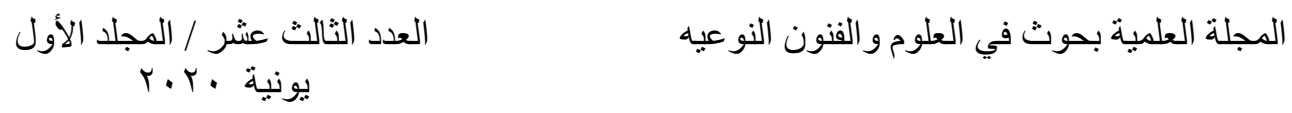

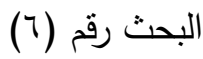

التكنولوجيا النظيفة وعلاقاتها بالتصميم الداخلي

عبد الوهاب سالم الرشيدي

مدرب متخصص ج

الهويئة العامة للتعليم التطبيقي والتلديب

كلية التربية الأساسية - قسم التصميم الداخلي 


\section{مقدمـة :}

يعرف علم البيئة الحديث ( الإيكولوجيا ) بأنها الوسط أو المجال المكاني الأي يعيش

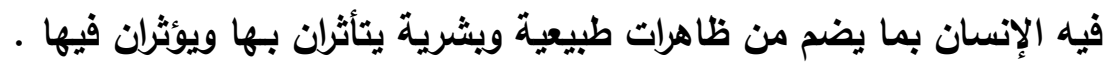

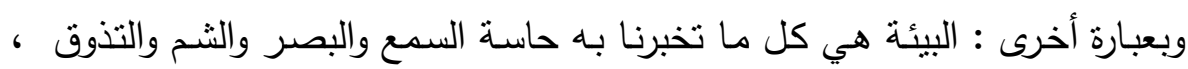

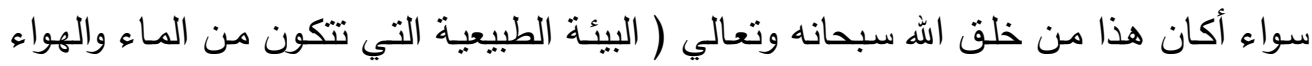

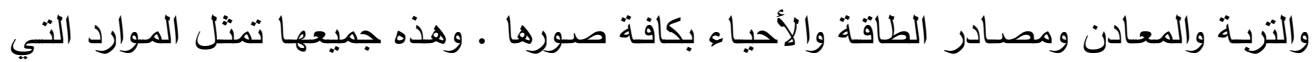

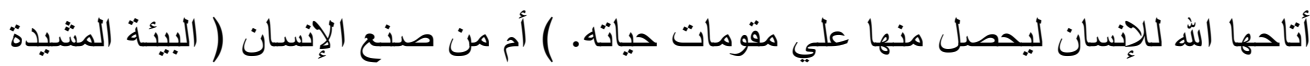

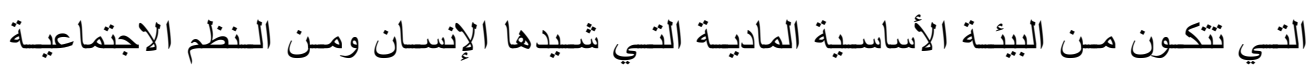
والمؤسسات التي أقامها ) ).

وقد أوجز إعلان مؤتمر البيئة البشرية الذي عقد في استوكهولم عام ب 19V1 _ مفهوم

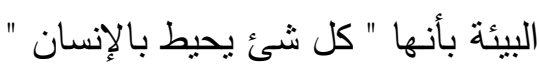

والبيئة هـي إطـار لا حـود لـه ، تهم كـل المجتمعـات الغنيـة والفقيـرة ، المتقدمـة

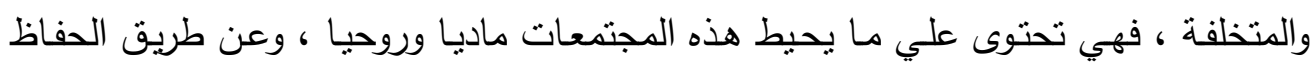

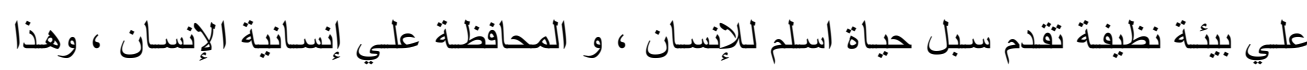

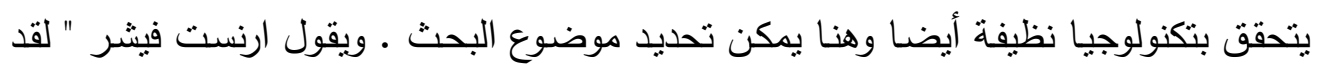
أصبحت التكنولوجيا هي القافلة التي تقوم بتوليد نوع جديد من الجمال " ( 1 ( ) . ولقد حافظ الإنسان قديما علي البيئة أما حديثا فقد أساء الإنسان إلى البيئة فلم يعد يحافظ عليها ، أما عن قصد أو عن جهل ، وبذلك يساهم في تدمير إنسانيته بدون وعي .

(1) ارنست فيشـر .ضرورة الفن .ترجمـة أسـعد حليم ص 
وقد آن الأوان لنا ولدولنا أن تعيد للبيئة حرمتها ونظافتها بالتكنولوجيا وليس بتقليد بيئات أخرى

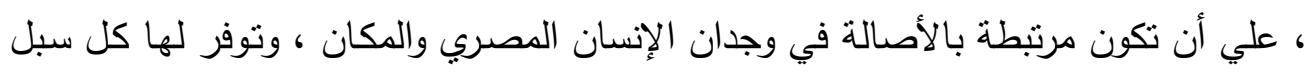
الحماية .

ويقول د/ حمدي خميس " فن العمارة الداخلية من أبرز الفنون اتصالا بحياة الناس وأساليب معيشتهم ، فالإنسان منذ القدم حريص علي الاهتمام بتتظيم المسكن الذي يأو يه ، ويحقق لـأله

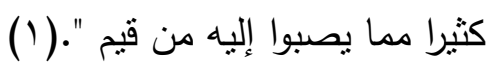

وشكل المسكن وكيفية إقامته يتأثران إلي حد كبير بييئته و بثقافة الفرد واتجاهاته الفكرية والاقتصادية والسياسية ، إذ أن لكل عصر من العصور ، بل لكل بيئة من البيئات فنا خاصا .

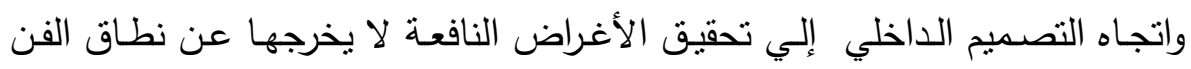

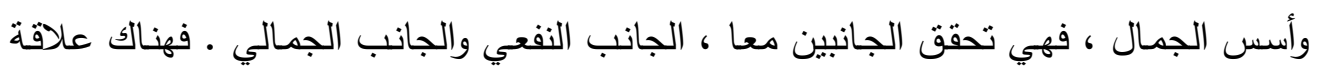
قوية بين الإنسان والتكنولوجيا وخاصة المصمح سواء أثثاء مرحلة التصميم أو مرحلة التنفيذ . ولقد ارتبطت تكنولوجيا الفراغ الداخلي بوجدان الإنسـان وقدراته وثقافته الفنية التي

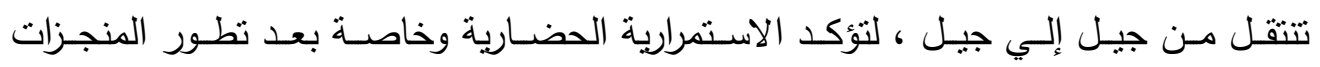
التكنولوجية بسرعة ـ وقد أدى ذلك إلي تعدد مؤكدات التصميم الداخلي في الثكل والمضمون

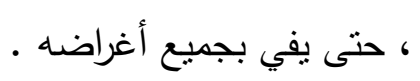

وتحتاج بيئة العمارة التصميم الداخلي بدرجة كبيرة إلي الثقنية والتكنولوجيا لتتحقق وتأخذ شكلها النهائي الذي يميز حضـارة عن أخرى ، ولقد تأثرت الكويت بالتكنولوجيـا

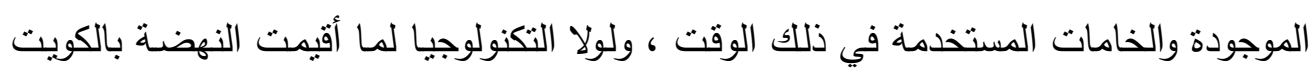

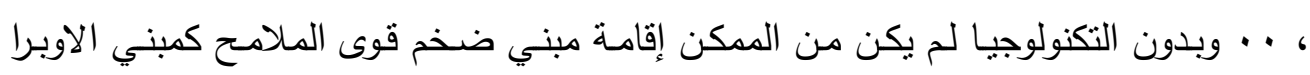

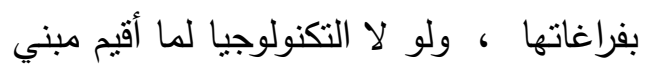


أبراج الكويت وبرج التحرير ، ولما وجدت عمارة حديثة ، وهي التي لو حللناها لوجدنا كل

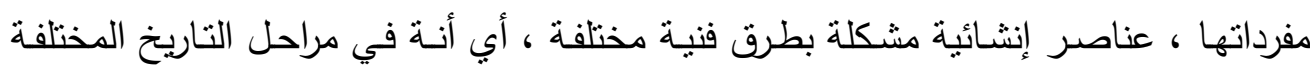

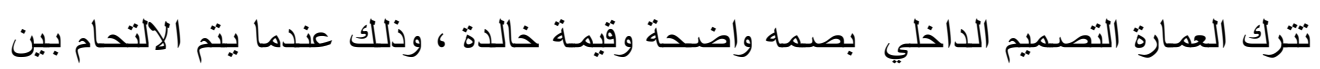
- الفن والتكنولوجيا

أمـا العمـارة عامـه التصميم الداخلي خاصـة فمنذ بدايـة القرن العثرين وحتى يومنـا هذا فكثيرا ما تقتق ذلك الالتحام بين الفن والتقتية . .

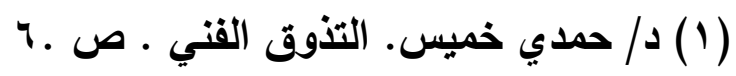

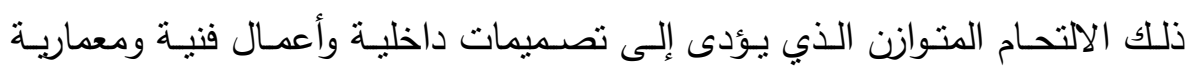

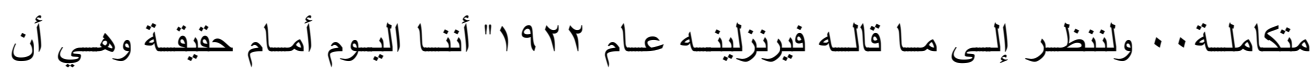

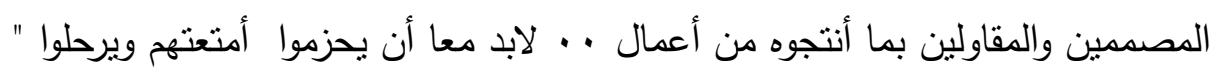
أمسا الاتحاد الألماني للصناعات الذي قامت فيهه مجموعـة من المعماريين والفنانين

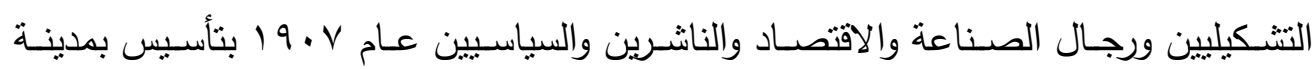

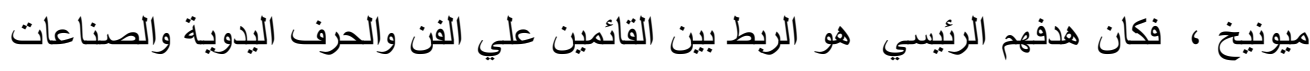

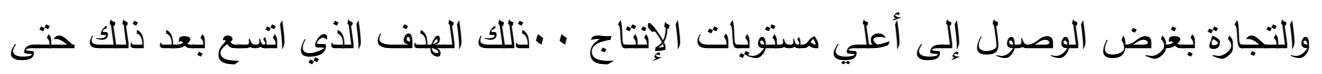

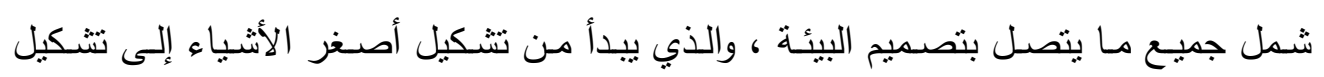

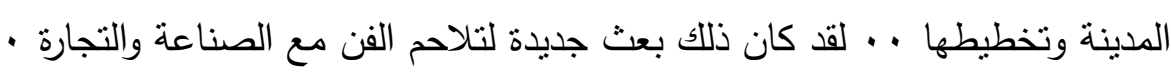
كمـا أن ألبـا وهـوس وهـي تلـك المؤسسـة الهامـة التـي تـأثرت بالاتحـاد الألمـاني

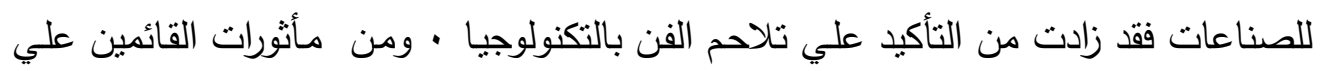

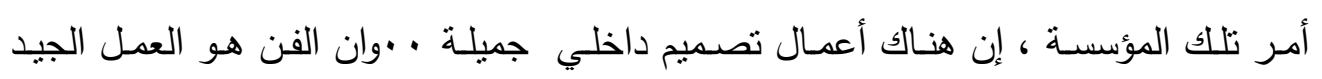

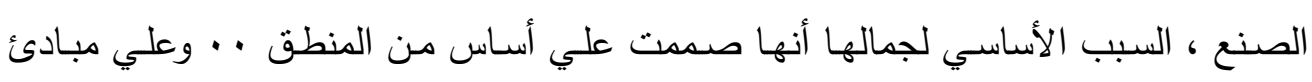
الوجود المنطقي للأثياء ، علي القوانين الطبيعية للمواد المصنوعة ، منها الدقة في التعبير

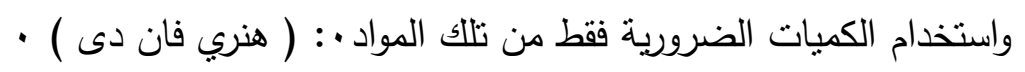




\section{التصميم الداخلي والتكنولوجيا :}

والتطـور العـلمي هـو المحرك لنظريـات التصـمبم ، فالتصـميم الـاخلي , مـرتبط

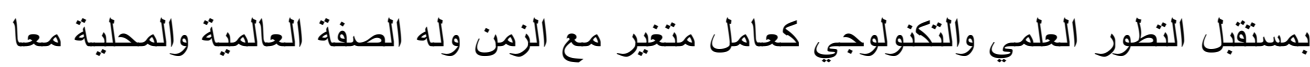

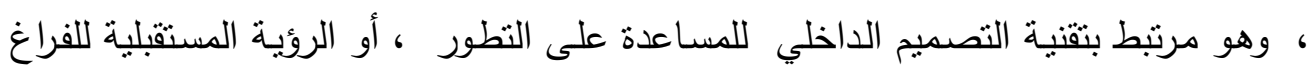
• الداخلي وتشكيلة

فالتصـيم الـاخلي الذي يواكب ذلك التـفق الهائل في العلم والمعرفـة في شـتي

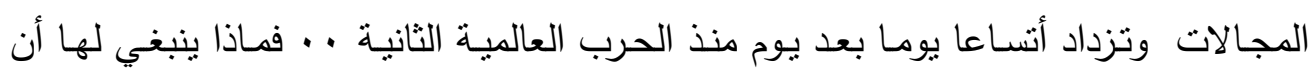
يكون ؟مسن الطبيعي أن يكون مـرآه لعصره، يعكس ذلك التقدم الكبير في العلوم الهندسية والتطبيقية في المصانع والورش · · حتى تكون أمينة في شهادتها علي العصر ل

ولكن واقع الحال يخالف ذلك ؟ ففي أحسن الأحوال قد نجد فراغات داخلية جيده من

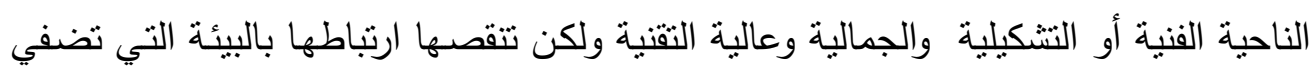
عليها ما تستحقه من قيمة فنية وبذلك نفقد التلاحم بين الفن والتكنولوجيا .

لقد أصبحت العملية التصميمية مركبة ومتاخلة بين تخصصات عربضة ومتتوعة ، حيث أصبحت المعارف التي شكلت خبره مصمم العمارة الداخلية القديم لا تكفي اليوم بآي

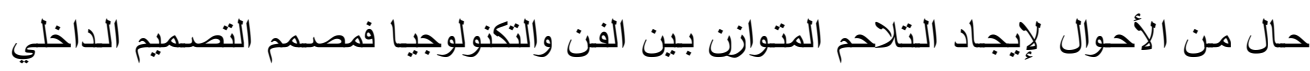

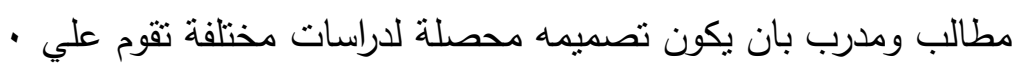

قإلإراسة الاجتماعية والثقافية واقتصاديات المشروع

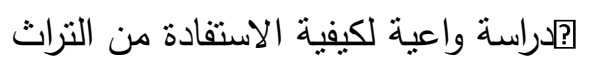
?دراسة وظيفيات الحيز ووضع التدريب المرن الذي يحقق ذلك في يسر وسهولة ?دراسة البيئة المحيطة لعناصر الحيز والفراغ الداخلي ?دراسة أنسب الطرق التكنولوجية في التنفيذ 
كما أن علية أيضا أن بيتخدم في ذلك إمكانات العصر . في الحصول علي المعلومات الأساسية ،في الورش والمصانع , كل تلك الدراسـات تحتاج لمعرفته بهندسة مواد البناء والخامات المختلفة وبالتركيبات الفنية.

فقلما نجد مشروعا يخلو من خطوط ضغط منوسط ، وأخرى للضغط المنخفض ،

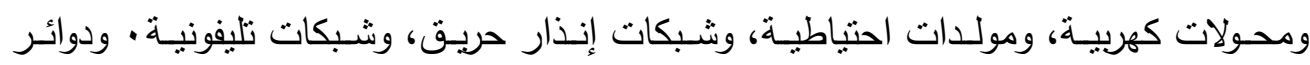

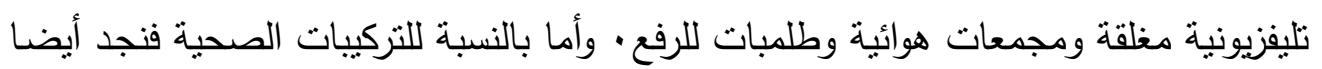

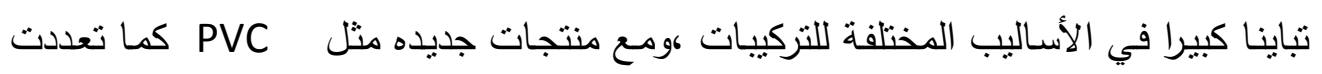

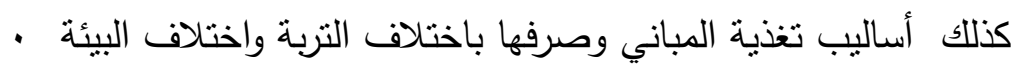

من كل ذلك نرى أن مصمم التصميم الداخلي , اليوم مطالب أكثر من آي وقت

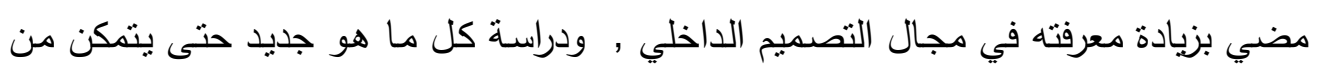

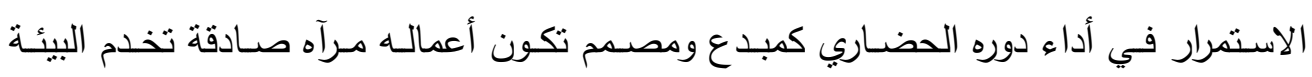

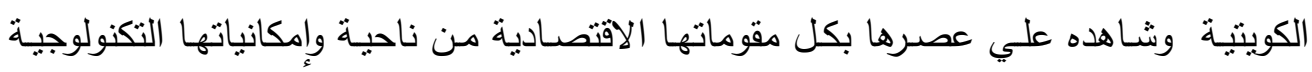
والتتفيذية من جهة اخرى .

إن الثورة التكنولوجيـة الحديثـة بـأت تغير مـن المعطيات الاقتصـادية والاجتماعيـة

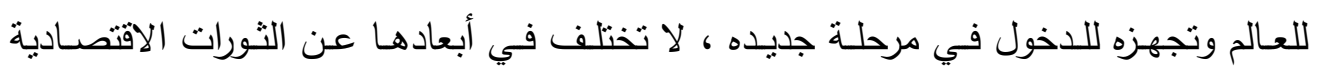

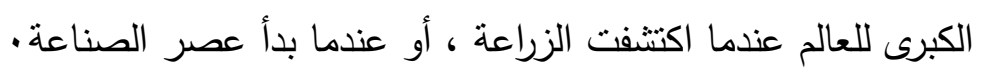

من أجل ذلك أصبح تعزيز النشـاط البحثي والتعليمي والعلمي والتكنولوجي معادلا لمعني وجود هذا الثعب العظيم بالكويت ، نقطة البداية هي التعليم بقصوره الواضح واعتماده

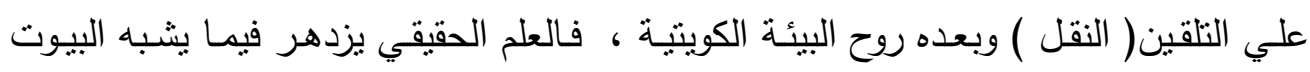

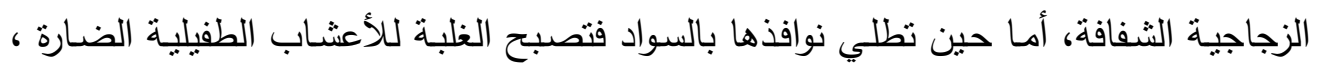

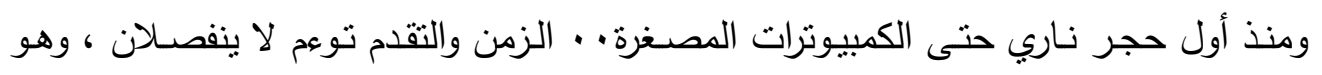

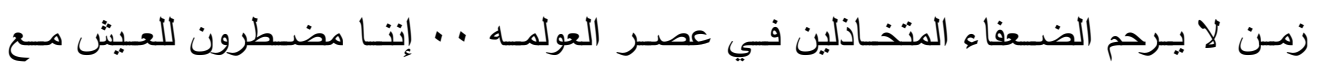


التكنولوجيا وبها ، فاستلهام الرسالة الإنسانية للتكنولوجيا يتجه بنا صوب المستقبل ووضعنا التاريخي منوط بمسئوليات هائلة .

والتكنولوجيا ظاهرة جماعية واجتماعية تولدها ظروف مجتمع معين تتوافر لدية سبل

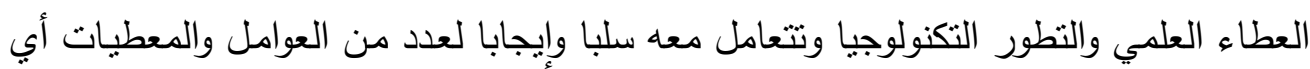

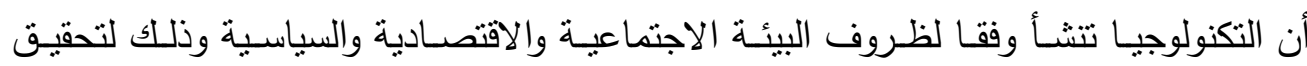
احتياجات مجتمع هذه البيئة ومن ثم فهي تتغير بتغير احتباجات المجتمع وقدراته ولهذا فان نمط التكنولوجيا المطلوبة إنما يصوغه المجتمع الذي تولد فيه هذه التكنولوجيا ويستمر نموها

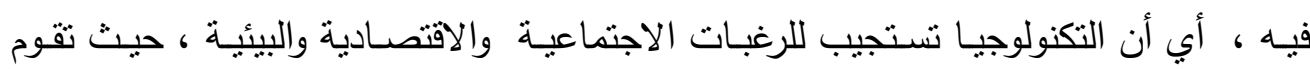

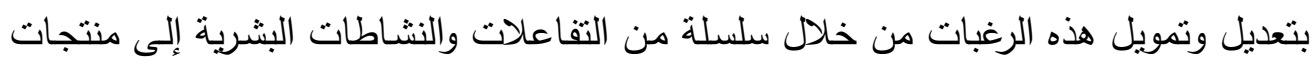

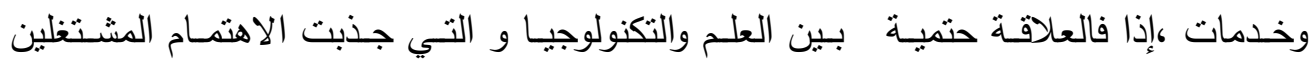

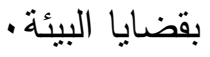

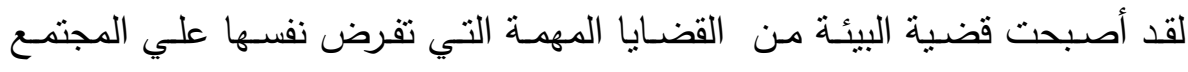
ولعلها تتضمن مفاهيم كثيرة منها مستوى الرفاهية والحياة والتقدم التكنولوجي .

من هنا بتضـح أن البيئة النظيفة تعتمد أساسـا علي القدرة الذاتيـة للمجتمع والمتمنلة

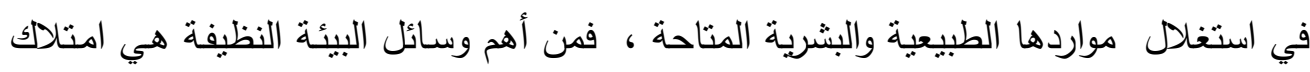
القدرة العلمية والتكنولوجيا.

ولعل من أهم المصادر التي تعمل علي المحافظة علي البيئة وأحداث النطور :. • مصدر داخلي ينبع من القدرة علي التجديد والابتكار داخل المجتمع الذي ينعكس أثرة

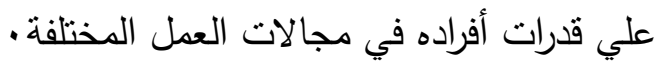

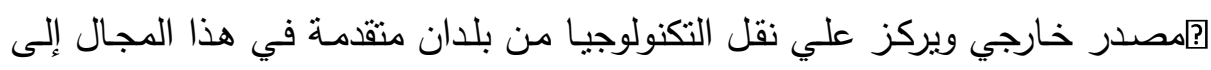
· الكويت 
وتتتقل التكنولوجيا عن طريق الثركات الاستشارية التي تصمم ، ثم شركات المقاولات التي

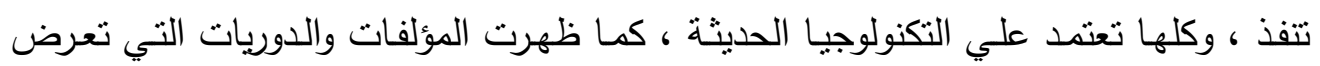

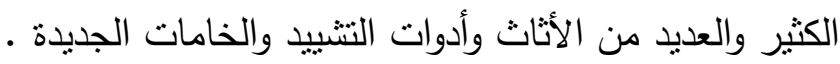

من هنا كانت أهمية تطويع تكنولوجيا تصميم الفراغ الداخلي لتتجاوب مـع منطلبات

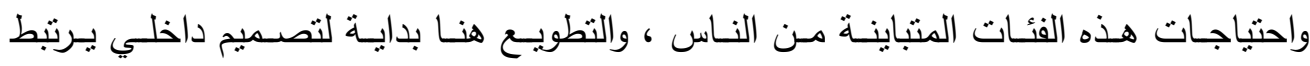

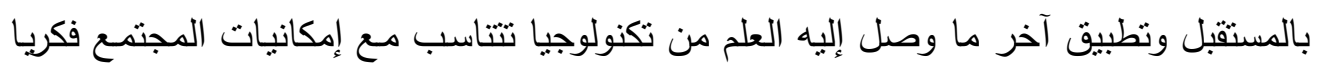
وعلميا وعمليا ، كما تتتاسب مع موارد الدولة ماديا واقتصاديا وبيئيا .

والتطور العلمي هو المحرك لنظريات التصميم ، فالتصميم الداخلي مرتبط بمستقبل

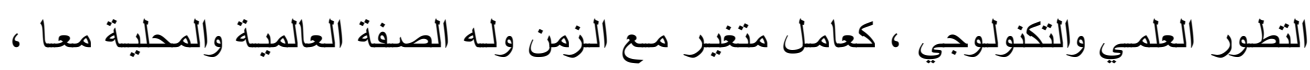

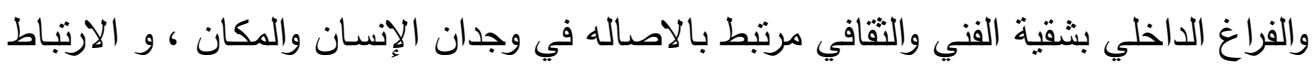

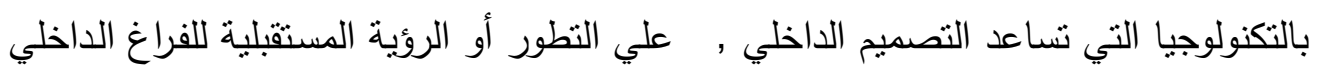

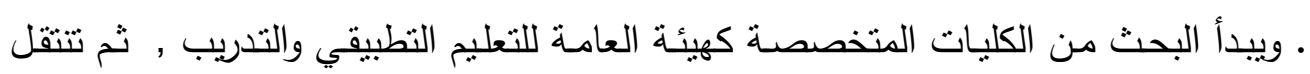
النتائج إلى المصانع وتتنهي إلى المستهلك. فالفرق بين التطور العلمي و بين التغير الفني ، يمكن القول بأن العلم يتطور ، بينما الفن بتغير " فالعلم يبدأ بنظرياته وقوانينه ومعادلاته ، ثم يتطور بطبيعة الحال مع تطور الحياة

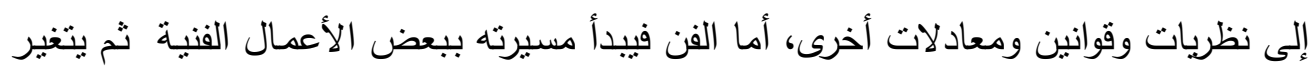
بطبيعة الحال مع تغير الحياة إلى أعمال فنية أخرى لها لون مغاير ، فالفن من وظيفته إثراء

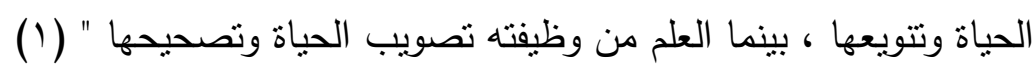


فبيئة التصميم الداخلي تشمل وحدة العمل ووحدة الفكر ، وبالتبعية وحدة التشكيل ، فالفراغ الداخلي لبس فراغا مجردا أو خاويا ، ولكنه متكامل مع ما بـه من تجهيزات أو أثناث ثابت أو متحرك ، فإن عناصر التجهيزات الداخلية مرتبطة بالثكل الخارجي..

ويقـول الــكتور لـويس عطـوه فـي كتابـهـ البنــاء التكنولـوجي للبــــان النامبـة " إن التكنولوجيا ظـاهرة جماعية واجتماعيـة تولدها ظروف مجتمع معين تتوافر لديـة سبل العطاء

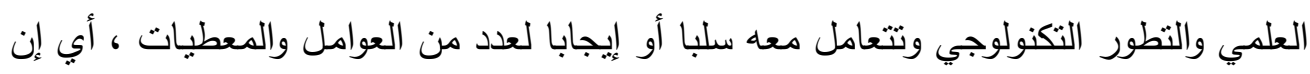

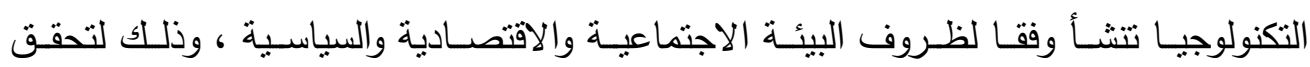
احتياجات مجتمع هذه البيئة ، ومن ثم فهي تتغير بتغير احتياجات المجتمع الذي تولد فيه وليه

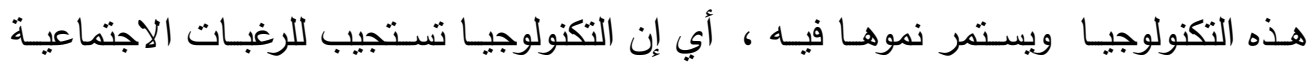

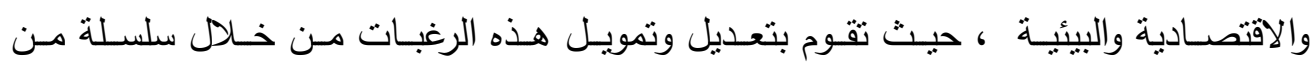

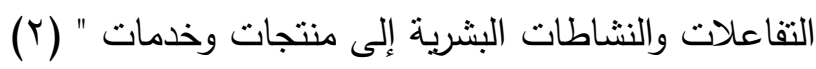
ولا يمكن أن ننسـي العلاقـة بـين العلـم والتكنولوجيـا والمجتمـع التي جذبت اهتمـام

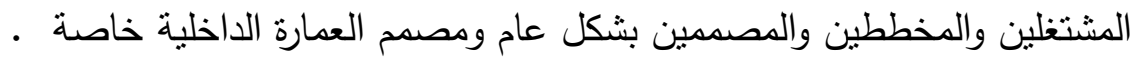

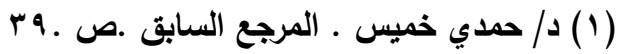

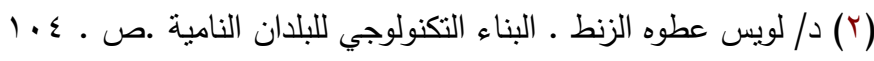


التقدم التكنولوجي لصناعة بناء فراغ داخلي نظيف :

تخضع صناعة بناء الفراغ الداخلي للإمكانيات الاقتصادية والتكنولوجية المتوفرة في أي دولة

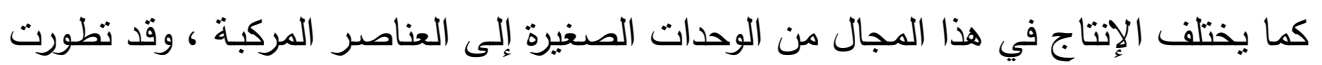
صناعة بناء

الفراغ الداخلي في كثير من الدول المتقدمة وظهرت آثارها علي نطاق واسع في كثير من التجمعات البيئية في هذه الدول.

وقد صـاحب إنثـاء المباني في بـادئ الأمـر بعض القيود التكنولوجيـة بمـا لا يدع للمصدم

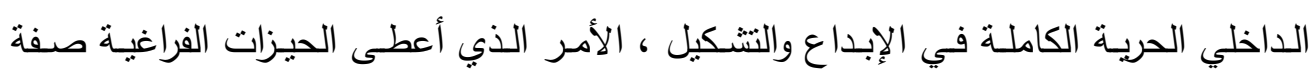
الجمود والعجز عن التعبير الإنساني للعمارة الداخلية

من هنا بدأ كثير من المصممين يخشون علي التراث الحضاري للتصميم الداخلي في

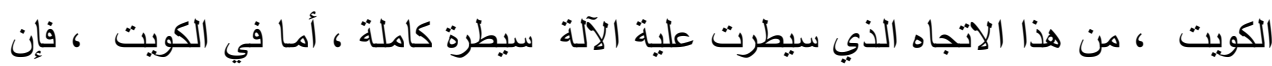
تصنيع مـا بداخل الحيزات الفراغية لا يزال يبحث عن مدخل ينتشر منـه نظرا لعدم ملائمـة

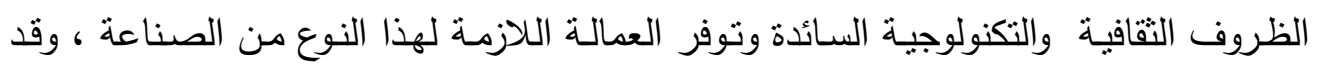
بدأت هذه الصناعة تدخل الكويت عن طريق الثركات الأجنبية دون أن تبني معها قاعدة

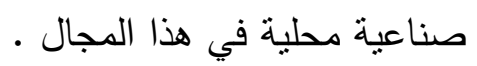

الأمر الذي يعطينا فرصة أخرى لمراجعة نفسنا أمام هذا التيار التكنولوجي في عصر

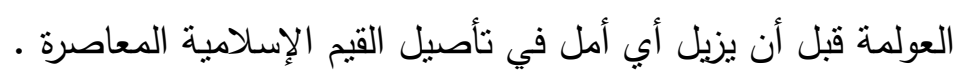


ولقد فطن كثير من العاملين في هذا المجال إلى خطورة هذا الاتجاه فعددوا إلى

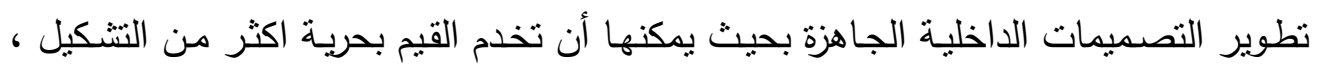
وظهرت في هذا المجال أمثال كثيرة والتي خضعت إلى التصميم الحر ، ولكن لابد من مراقبة

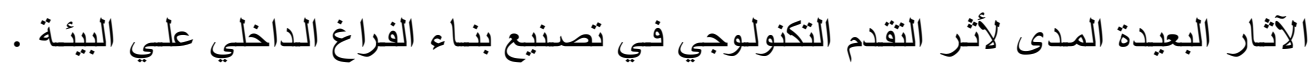

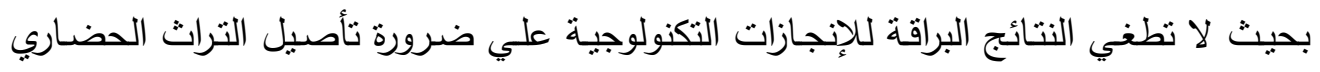

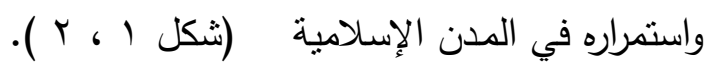
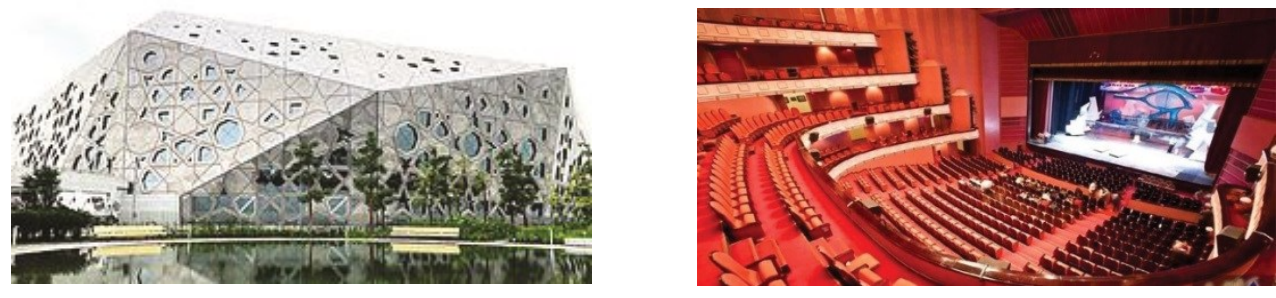

$$
\text { شكل(1) مركز الثيخ جابر الأحمد الثقافيمن الداخل شكل(r) مركز الثيخ جابر الأحمد الثقافيمن الخارج }
$$

ويتضـح من ذلك أن تطور صناعة بنـاء الفراغ الداخلي لا بـد من أرتباطـة بشكل

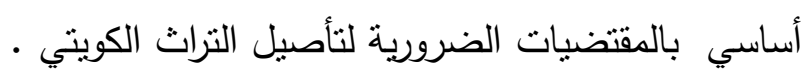

وصـاعة بنـاء الفراغ الداخلي تختلف عن غيرهـا مـن الصـناعات خاصـة بالنسبة

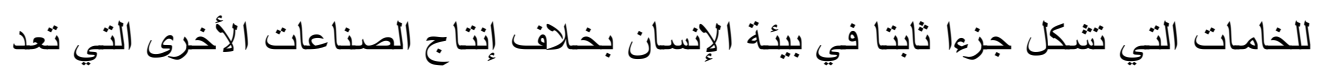

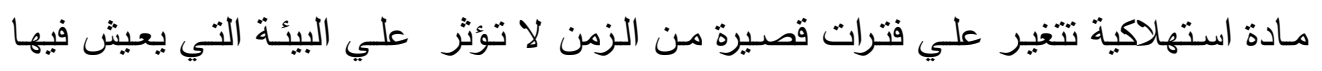

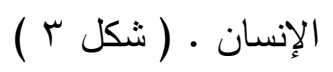




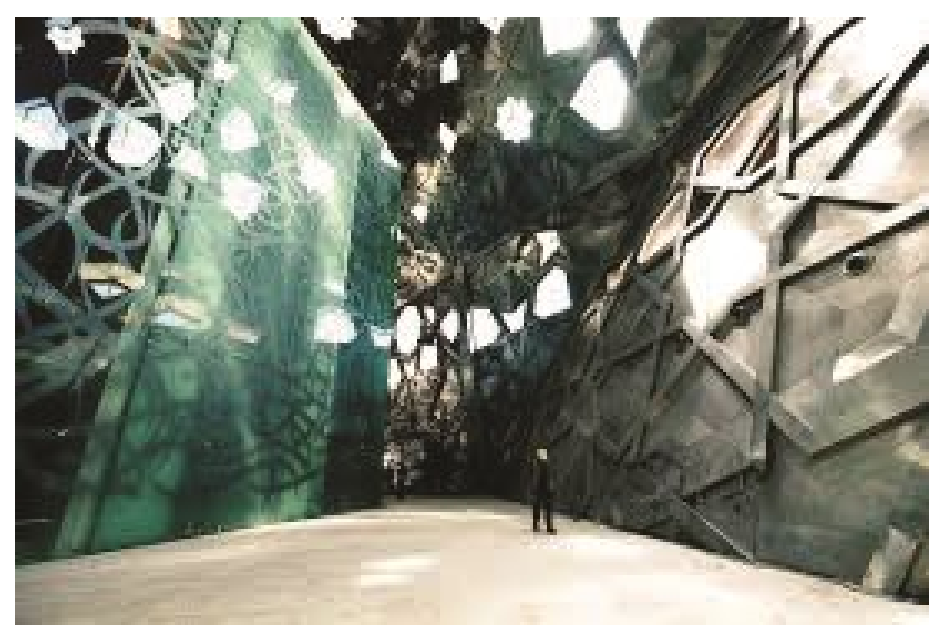

شكل (r) التكنولوجيا تؤثر كثير ا علي البيئة التي يعيش فيها الإنسان

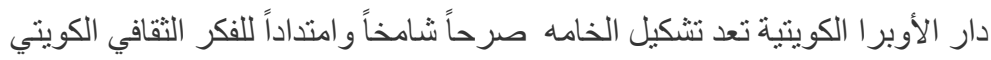

إن عملية تصنيع ما بداخل بيئة الفراغ لا بد وان يرتبط بالجوانب الإنسانية للتشكيل

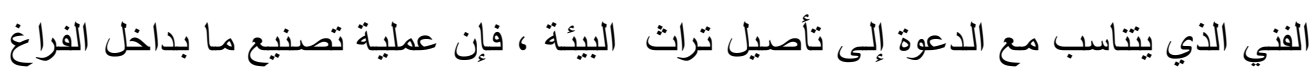

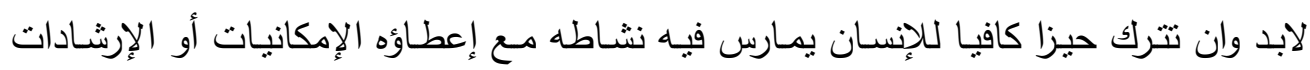

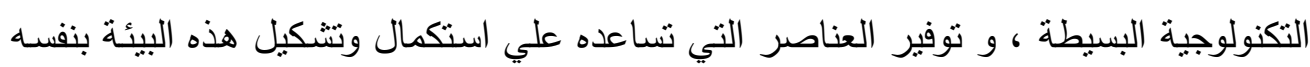

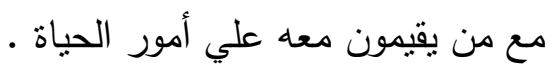




$$
\begin{aligned}
& \text { المجلة العلمية بحوث في العلوم و الفنون النوعيه العدد الثالث عشر / المجلد الأول }
\end{aligned}
$$

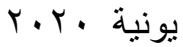

ومن هنا يمكن أيجاد اللمسات الإنسانية ليس فقط داخل الحيز السكني بل كذلك في

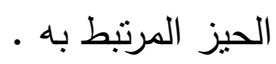

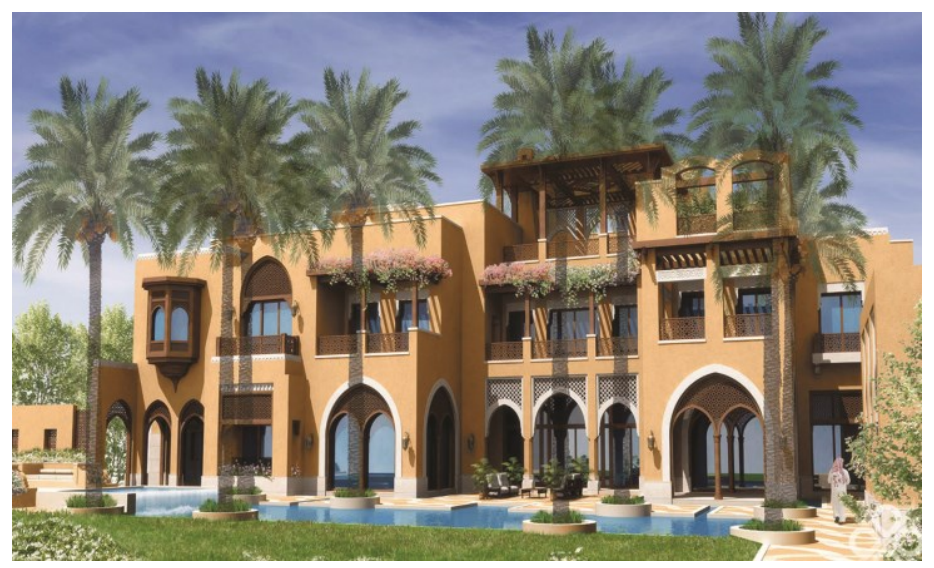

شكل ( ع ) تداخل الفراغات في المسكن الإسلامي الحديث

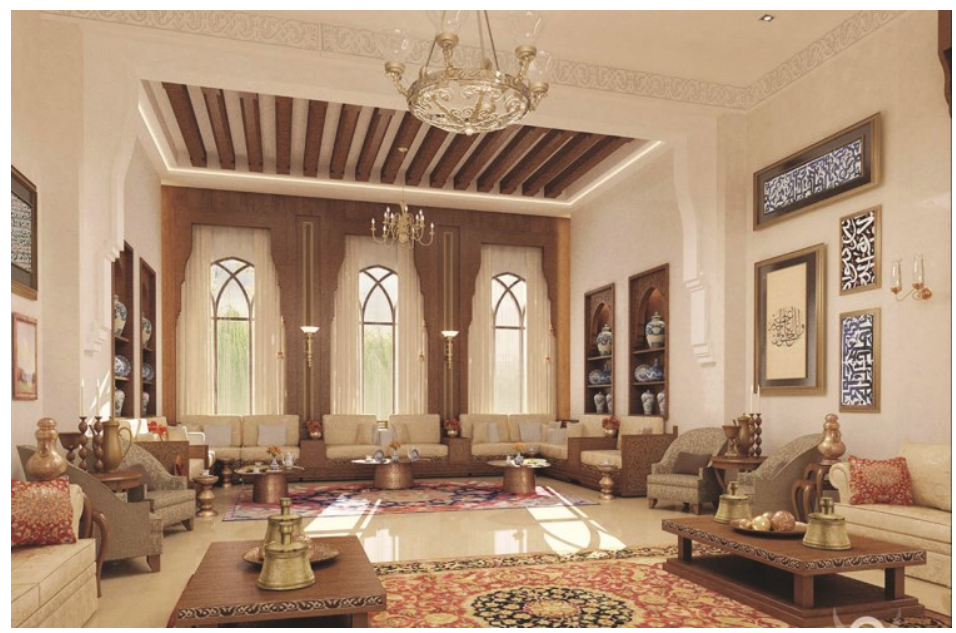

$$
\text { شكل (0) العودة إلي الزخارف الإسلامية }
$$


هذه ترنبط بإمكانية تطوير المنتج ، وتتقسم إلي تكنولوجيا المنتج وتكنولوجيا وسائل الإنتاج وهي تكنولوجيا المواد والخامات المستخدمة في قطاع التتفيذ والتشبيد التي يتم تشكيلها

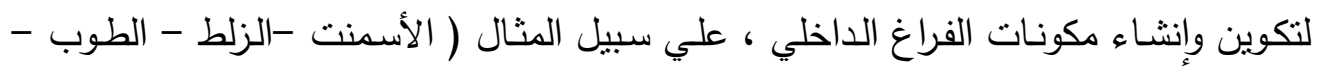

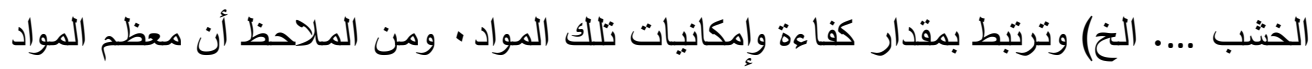

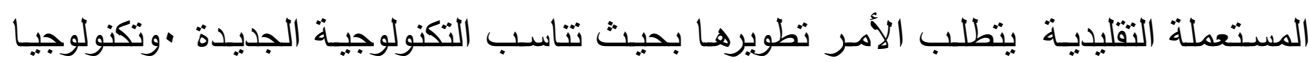
وسائل الإنتاج ترتبط بالطريقة التي يتم بها تشكيل الهيكل الفراغي العام للبيئة الحيطة . إن شاعرية المكان هي الألفة التي تصون قدرة العقل علي تذكر المكان فتصور حالة

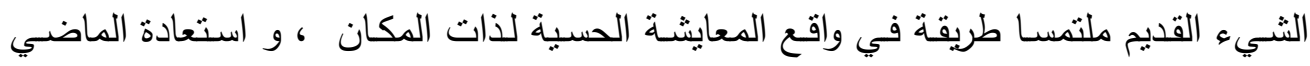

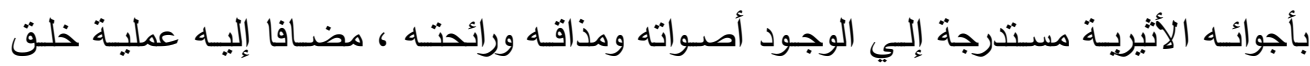
إبداعية تتلمس طرقها إلي الوجود لتعرض نفسها مرئية مجسدة .

استخدام الوسائل التكنولوجية في صناعة وبناء بيئة فراغية داخلية :.

إن الوسائل التي يتعامل معها مصمم التصميم الداخلي في صناعة وبناء بيئة الفراغ

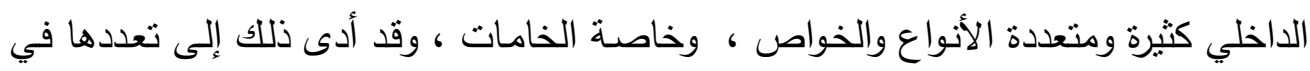
الثكل والمضمون حتى تفي بجميع الأغراض ل

ومن هذه الخامات علي سبيل المثال ، الخرسانة غير المسلحة CONCRETE

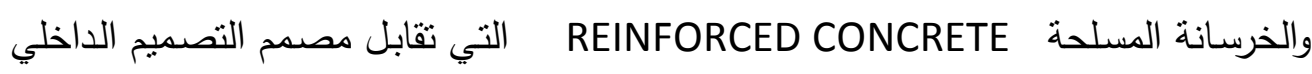
في شكل الأعمدة والكمرات ، وبلاطات الأسقف والسلالم ، وبرغم أن الخرسانة أحدثت اتصالا

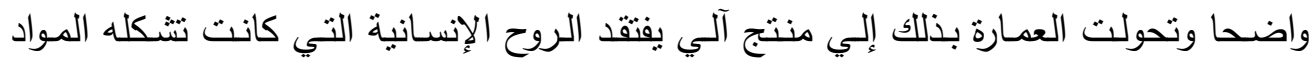

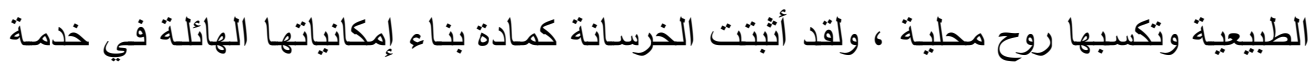

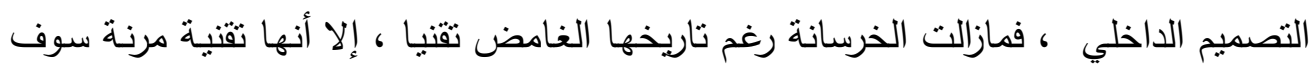
تحقق حاجات الإنسان في المستقبل ويصبح يبدل في مسكنة اكثر بكثير من ساكنها الحالين 
، وان أي تقنية مستقبلا يجب أن تسمح بالتغير ، ويجب أن يكون هذا التغير اقتصادي وأقل

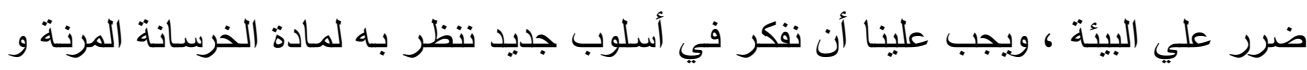

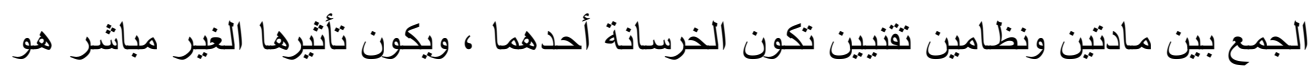

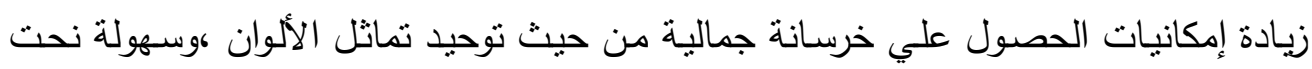

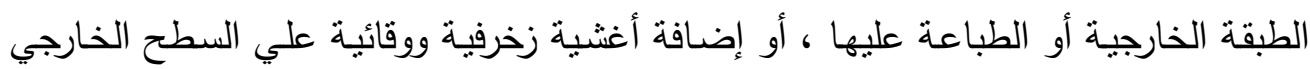

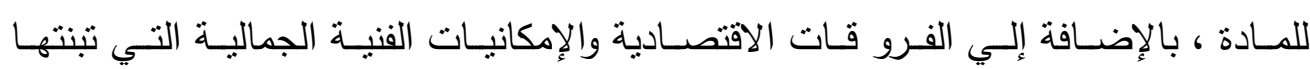
التكنولوجيا الحديثة .

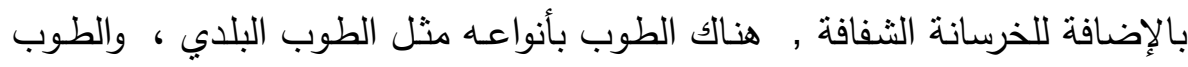

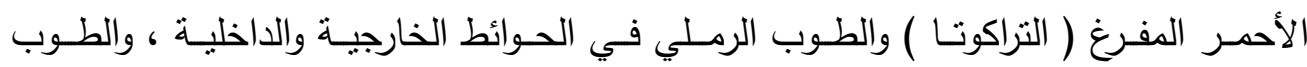

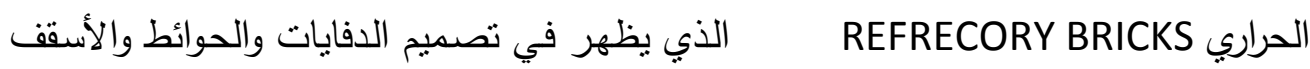
المصنوعة من الأخشاب أو الثبك الممدد ، وبلاطات السيراميك والرخام بأنواعه وألواح الهارد

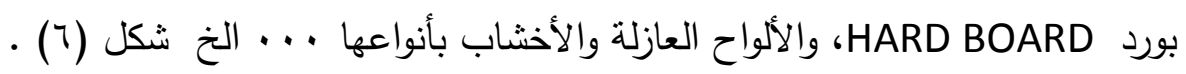

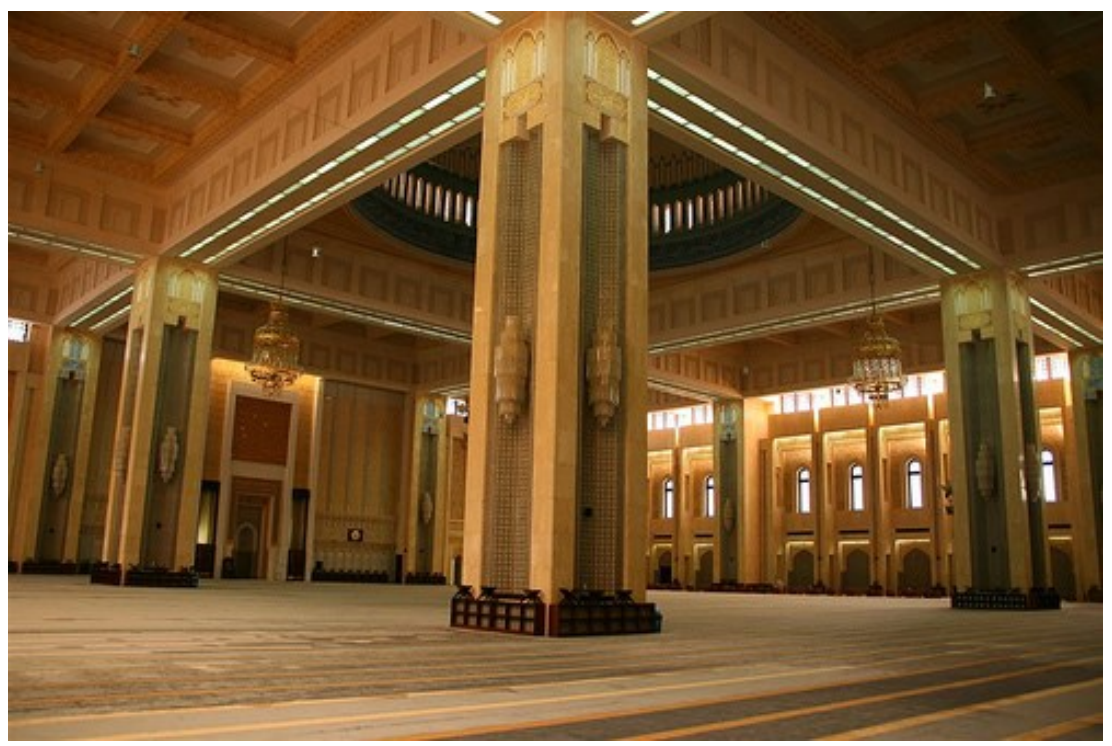

شكل (†) الخرسانة في خدمة التراث والبيئة الداخلية 
وبنـاء بيئة الفراغ الداخلي هو أساسـا نشـاط تكنولوجي يعتمد علي تحقيق الإحساس

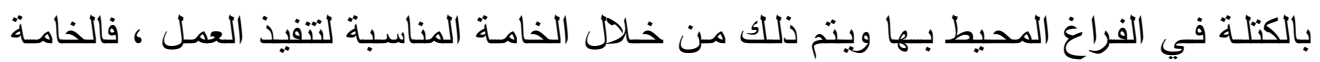
المثلي لتتفيذ أعمال بناء بيئة الفراغ الداخلي والتي يقدم فيها المصدم الشكل المعبر عن الفكرة والتي من خلالها يمكن إضافة قيما تزيد من الثراء التشكيلي للعمل ، هذه الخامة ظلت دائما هي الحلم الذي ينثده كل المصمين علي مر العصور

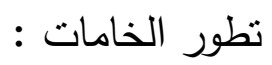

لقد نطورت الخامـات تطورا كبيـرا بعد التعرف علي الخواص الطبيعيـة للمـادة من

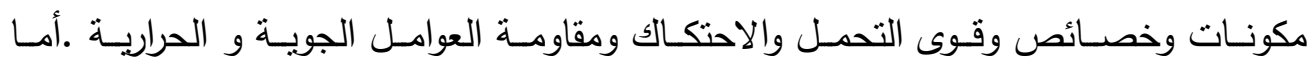

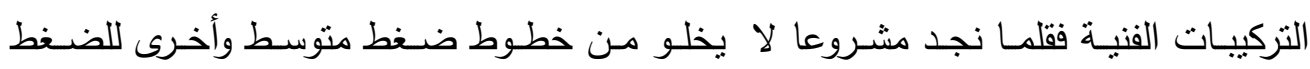
المنخفض ، ومحولات كهربية ومولدات احتياطية وشبكات إنذار حريق وشبكات ثليفونية ..

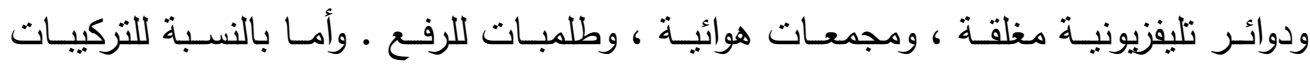

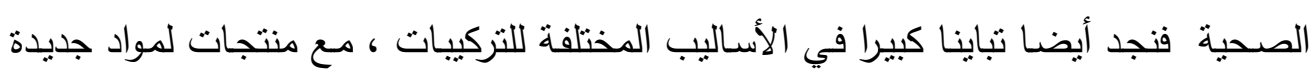
منت الباستيك ، والكوريان POVOCO KORIAN

ولقد عرف البلاستيك منذ حوالي قرن من الزمن ولكن لم يؤدى دورا فعالا في أعمال

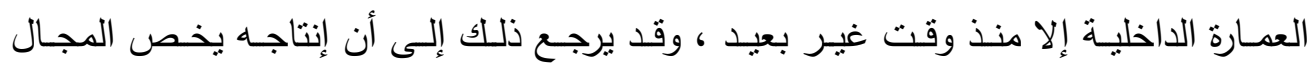

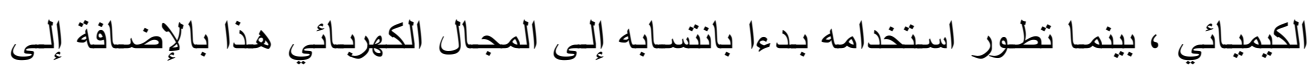

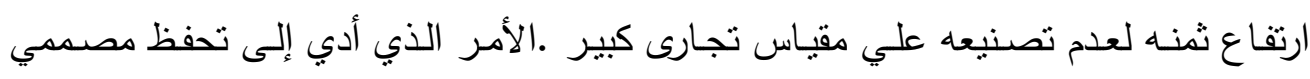

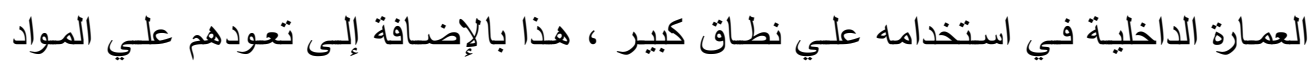

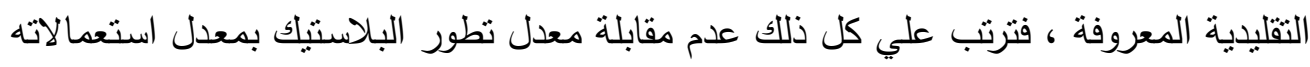
.ويمكن حصر استعمالات البلاستيك في مجال العمارة الداخلية لما يلي : ..

•الأرضيات ـ وتصنع علي هيئة بلاط أو صفحات من الفنيل وتلقي نجاحا كبيرا إذ أنها

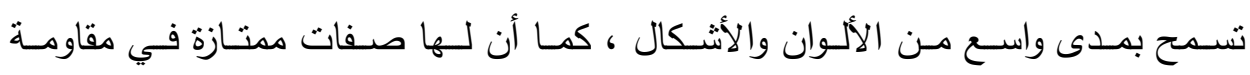

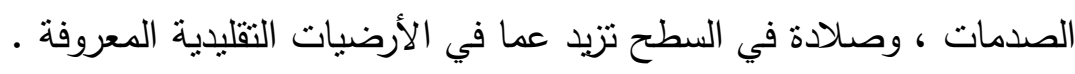


•حوائط الحمامات والمطابخ • تغطي تلك الحوائط ببلاط مصنوع من البولستر ين ويتميز

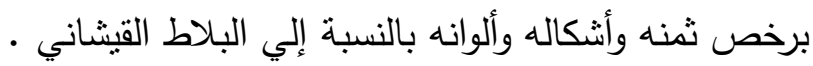

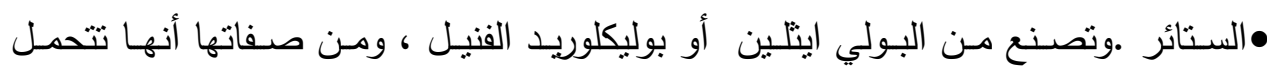

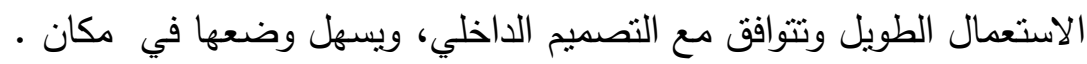

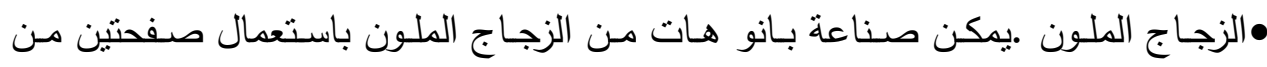
البلاستيك الثفاف يوضـع بينهما ملونات وصبغات وحصى صغير وشرائح فلزيـة وغيرها في تنسيق فني ( بسخن بالأشعة تحت الحمراء ) وينتج وحدة متماسكة بمكن بها تجليد أماكن معينة . •الطـلاء التخليقي • وذللك بإذابـة بعض مـواد البلاستيك في محاليل خاصـة لاستعمالها

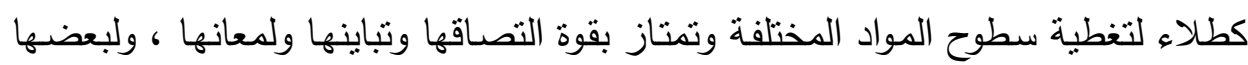

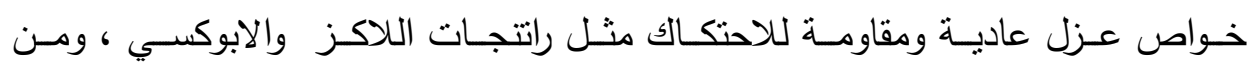
التطورات الحديثة في الطـلاء استعمال مستحلبات البلورات في البويـات لنتيـت مـواد البلاستيك في الماء أو بواسطة مثبتات .

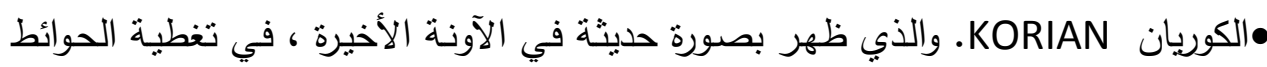

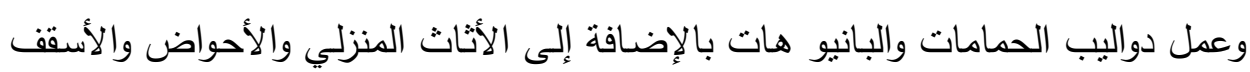

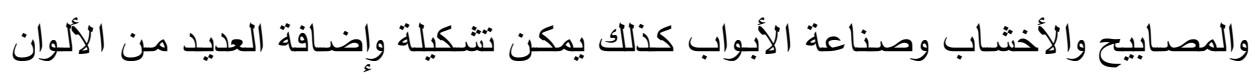

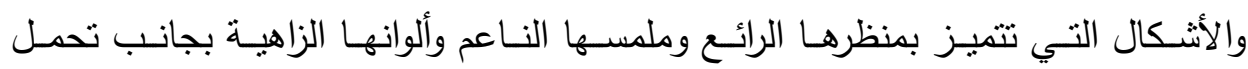

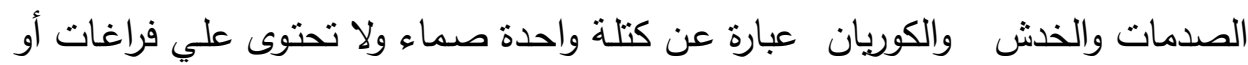

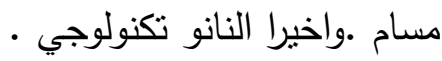




\section{استعمال القوا طيع الجبسية في بيئة العمارة الداخلية :}

مازلنـا حتى ألان في الكويت نستخدم الطوب بأنواعـه المعروفة في بنـاء الحوائط الداخلية ، وهي العملية التي تتكلف جهدا ووقتا ومالا يمكن توفير جزء كبير منها باستخدام

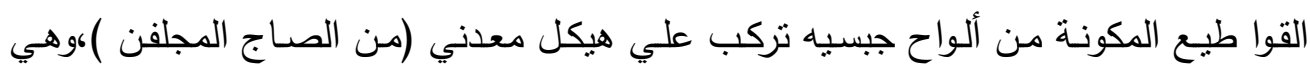

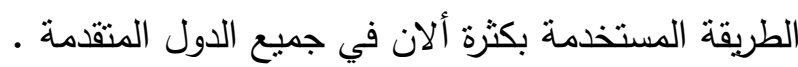

واستعمال الألوان الجبسية في عمل القوا طيع الداخلية لها مميزات مختلفة منها : ا. إن هذه القوا طيع ذات وزن خفيف جدا ( لا يزيد عن • \% من وزن الحوائط من

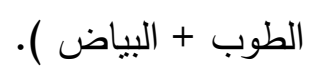

r. السـرعة الكبيرة في تتفيذ هذه القوا طيع ، حيث أنها لا تحتاج بعد عملها إلا إلى

$$
\text { وجهين من الدهان أو لصق ورق الحائط . }
$$

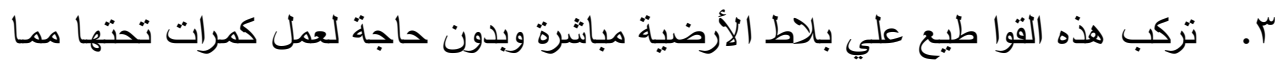

يمكنها من فكها في أي وقت وإعادة تركيبها في أي موقع آخر بالمباني عند الطلب .

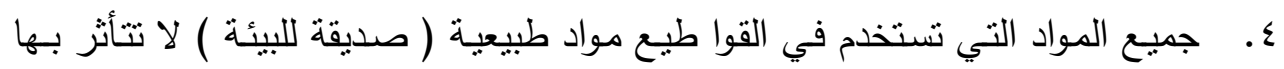

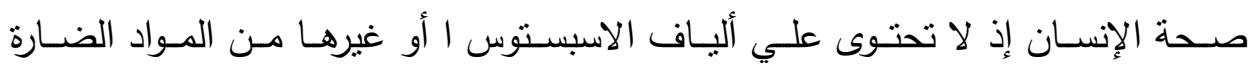
بالصحة .

وتتكون هذه القوا طيع من ألواح الجبس السيليزي ( جبس + ألياف سيليلوز ) بنسبة 10 \% إلى 10 \% بالترتيب وينت خلط المكونين معـا ، ثم يضـاف المـاء ويعرض الخليط

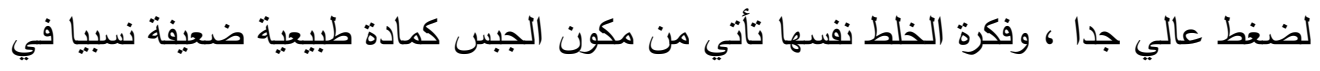

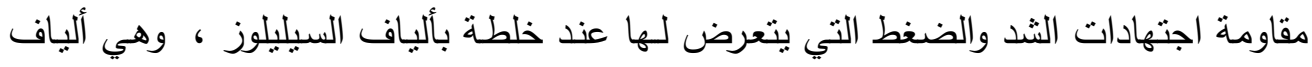
طبيعية نحصل عليها من الخشب أو الورق وفي النهاية تصبح كتلة لها مقاومة إجهاد عالية وتقوم ألياف السيليلوز بعملية الربط بين الجزئيات. 


\section{البديل العصري للاهانات التقليدية :}

بدأ العلماء في ألمانيا في الاستعاضـة عن الدهانات وأغطية الحوائط ، بما هو أوفر

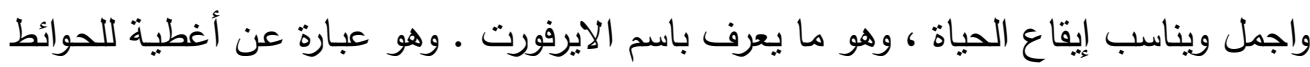

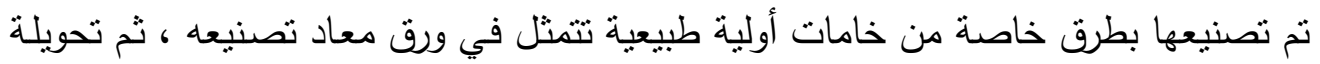

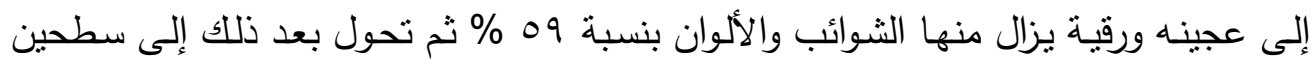
ورقين ونشـارة خشبية تنت معالجتها فنبا بوضـع الحبيبات الخشبية بين هذين السطحين لتنت عملية الدمج بينها بالضغط البخاري لتعطيها الثكل الهندسي النهائي المتتاسق ، ومن مميزاتها

•سهولة اللصق ويمكن لصقها علي أسطح مختلفة

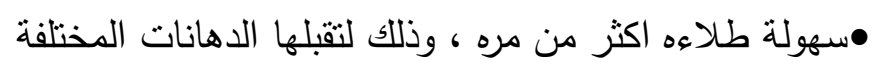

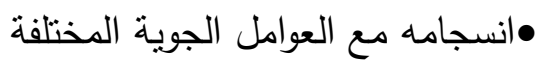
•القضاء نهائيا علي عيوب البياض النواضه •القضاء علي التلاعب في أعمال الدهانات •التكلفة الاقتصادية المنخفضة •إمكانية الرسم اليدوي علي ورق الايرفورت النئ

إن الاعوة لاستخدام بدائل تكنولوجية تعمل علي المحافظة علي البيئة مثل البلاستيك

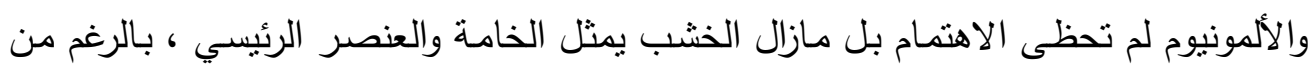

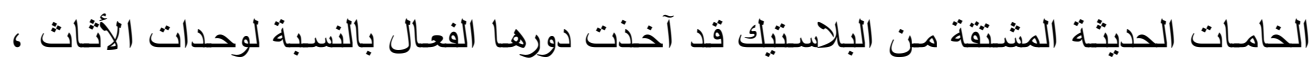

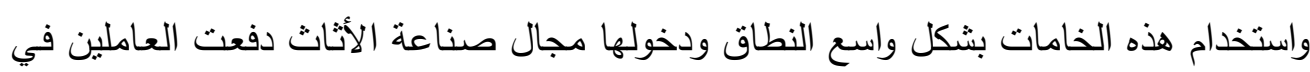
هذه المجالات إلى الابتكار واستخدام التصميمات التي تتفق مـع هذه المواد الحديثة التي ولتي

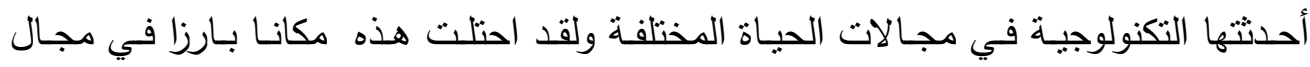
صناعة الأثاث عبارة عن بالونات تتفخ بالهواء فنتشكل البالونات إلى كراسي أو مناضد ....الخ 
ومـن اللـائن أيضـا نحصـل علي بعض الإكسسـوارات مثنل المقابض والمفصـلات والكرانيش، كذلك دخلت صناعة الألمونيوم في صناعة الأثاث ولا يقتصر في صناعة الأثاث

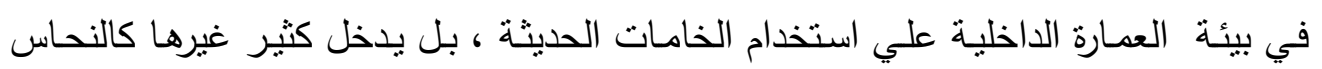

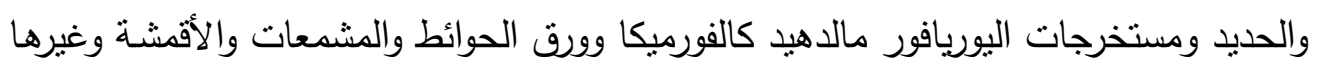
الطاقة السالبة وكيفية توفيرها من خلال تقنيات البناء :

ومن الموضوعات التي تمت بحثها حديثا موضوع استعمال الطاقة الثمسية والتبريد

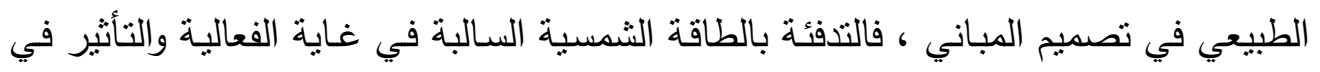

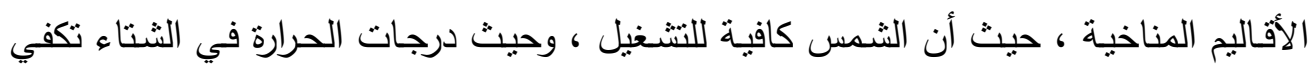

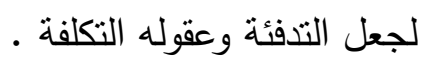

وتعتبر تكنولوجيا الطاقة الثمسية السالبة في أساسها تصميميه التوجيه ،وينبغي أن

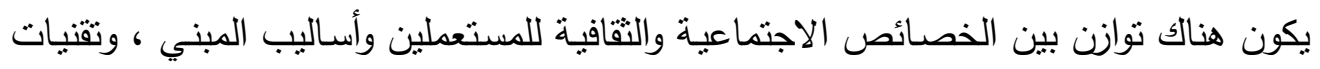

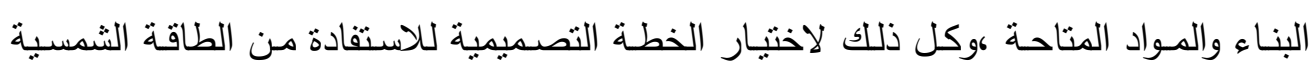
السالبة ،والتدفئة بالطاقة السالبة تمتاز بتوفير الطاقة والمساعدة علي تقليل الآثار البيئة للوقود

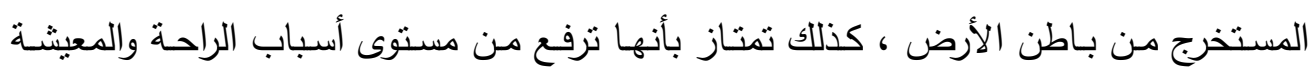

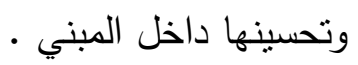

البناء التكنولوجي وعلاقته بييئة التصميم الداخلي إن التقدم العلمي والتكنولوجي الذي حدث خـلال سنوات القرن العشرين وحده يفوق عشرات بل مئات المرات ما حدث خلال آلاف السنين السابقة ، ففي الماضي كان المعماري

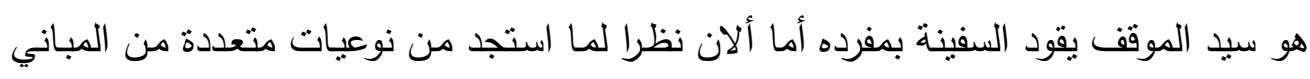

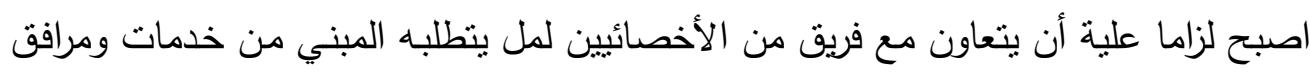

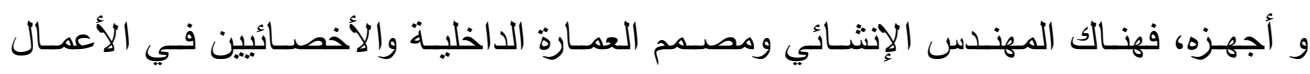

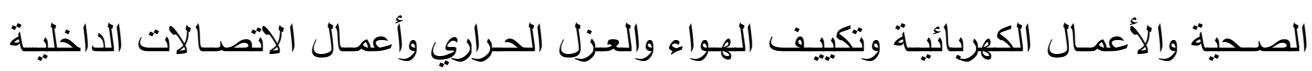


والخارجيـة والتأمين ضـد الحريـق والسـرقات والأثاث وحسـاب كميـات المواد وإعداد الجدوى الاقتصادية .

إن المفهوم الديناميكي لعملية التطور التكنولوجي تحدده احتباجات خطة العمل نفسها وفـق معطيـات الظـروف الموضـوعية لكـل عمليـة علـي حـدة ، فواقـع التطـور الاجتمـاعي

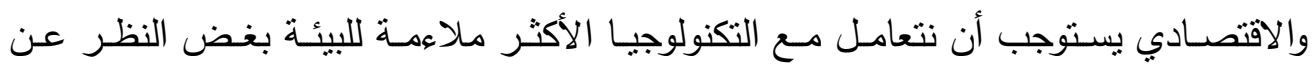

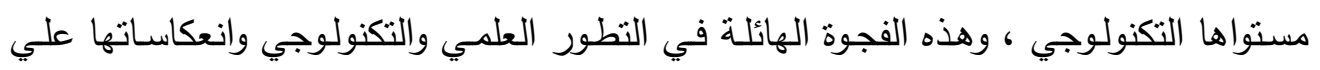

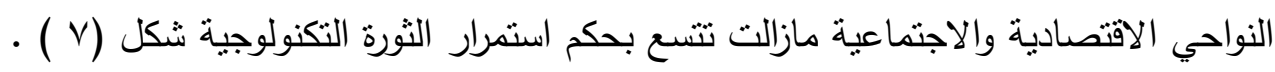

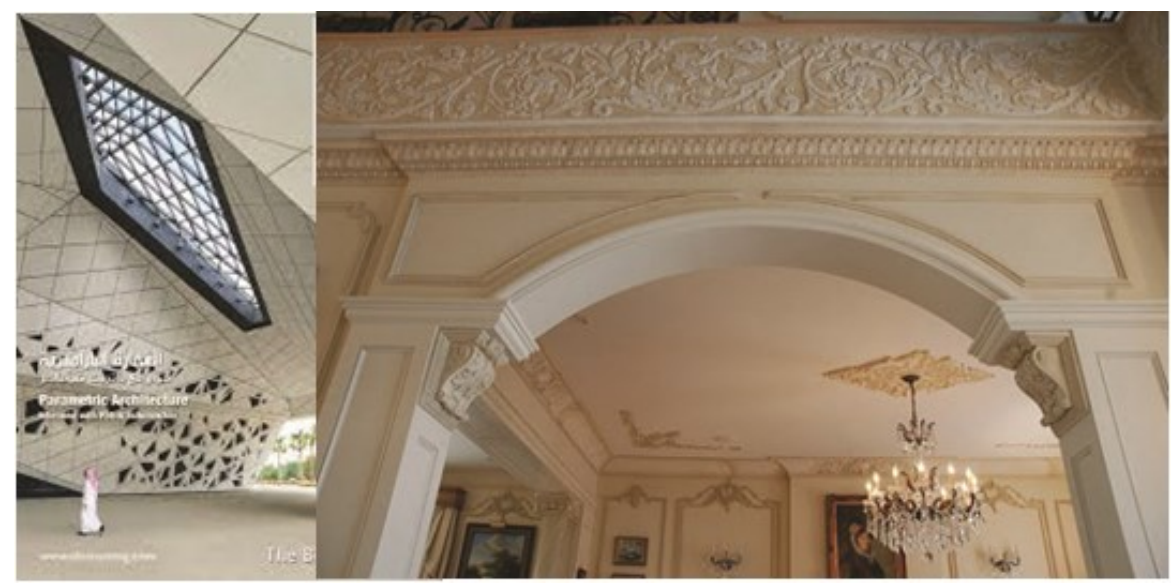

شكل (V) استخدام التكنولوجيا في تصميم وتتفيذ التراث القديم و التصميم الحديث

وان استخدام التكنولوجيا المتقدمة في بناء بيئة الفراغ الداخلي تعتبر مكلفة للغاية في

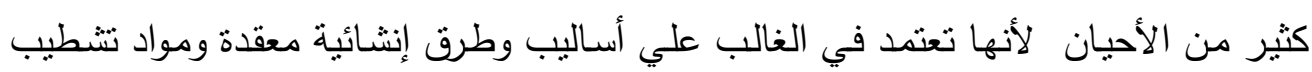

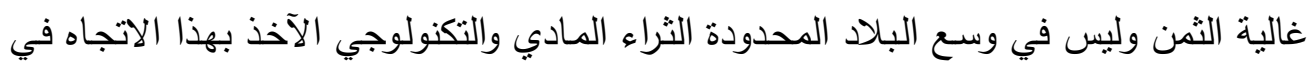

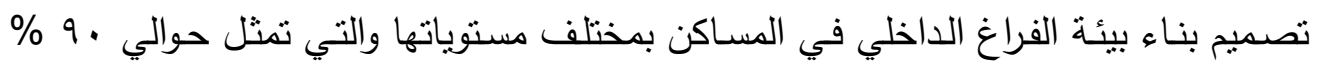

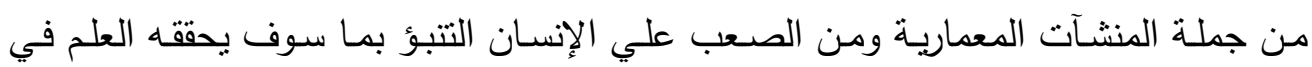

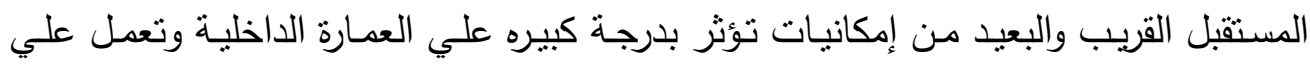

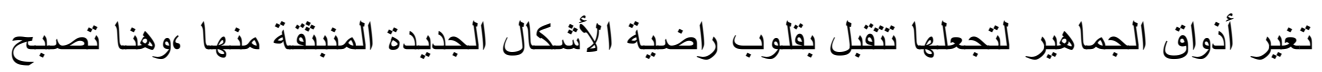


عملية بناء البيئة السكنية جزء لا يتجزأ من النشـاط اليومي ويصبح جزء منها لدي العامـة.

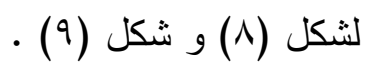

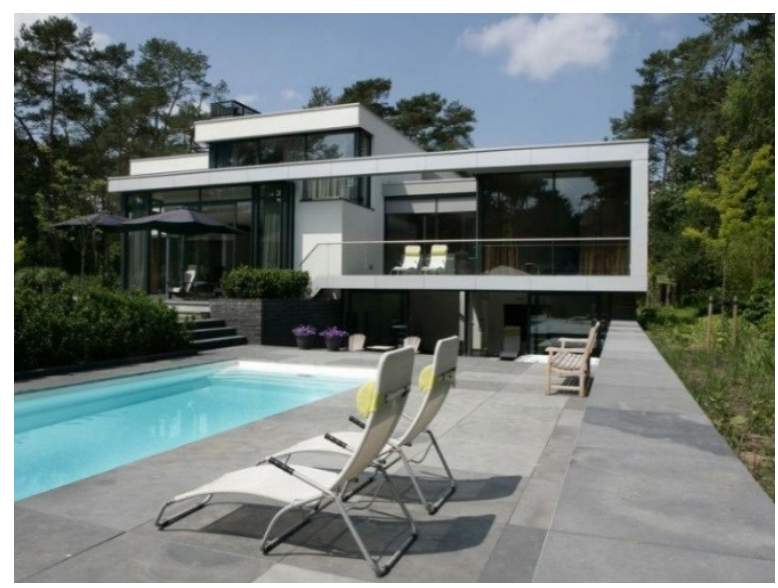

شكل (^) التكنولوجيا الفائقة في التصميم الداخلي

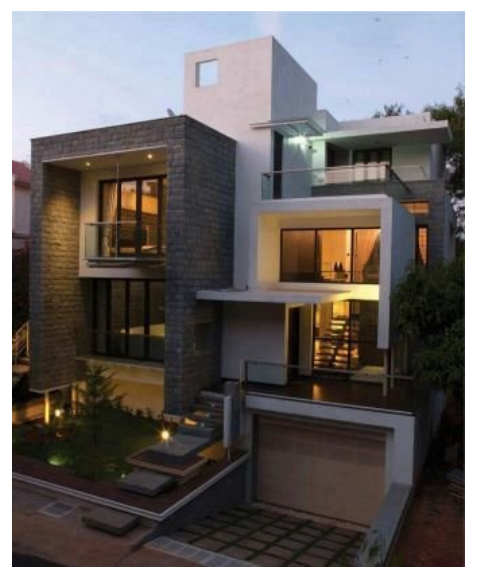

شكل (9) تقنيات البناء الحديث في الانشاء

إن تكنولوجيا المعلومات في عصر العولمة وإعادة هيكلة الاقتصـاد سوف تؤدى إلى

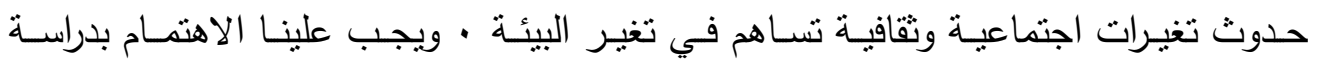
تأثيرات تلك التغـيرات على العــارة الداخليـة ، لأن التركيبـة الحضاريـة القادمـة واحتياجاتـها INT 
الفراغية سوف نقدما للمجتمع ، كما يجب علينا متابعة هذه التحولات التي تؤثر علينا سلبـا

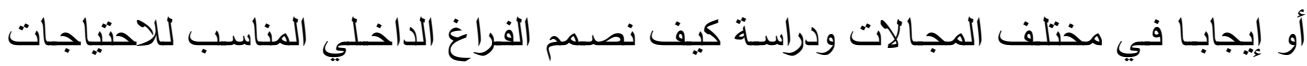

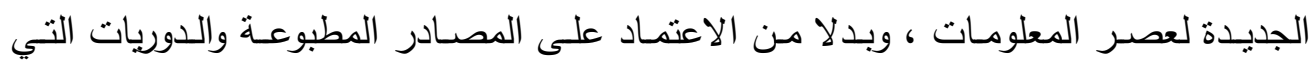

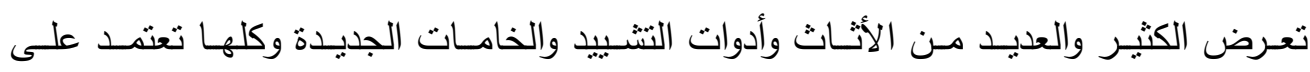
التكنولوجيا الحديثة وسوف نعتمد على مصادر المعلومـات الإكترونية التي تتميز بالتفاعل

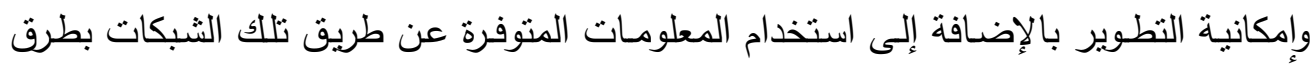
متعددة وتغيرات مفاهيم المكان والزمان والعلاقة الإنسانية ، فقد أصبح الإنسـان يعيش وكأنهـ في عالم واحد صغير متصل ، لذلك من الضروري تطوير مفاهيم العمارة الداخلية بحيث التيث

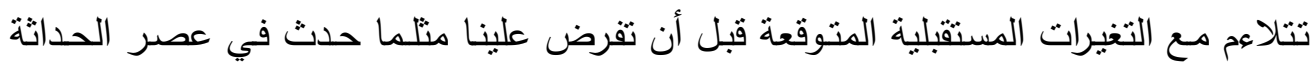
وما بعد الحداثة ، وذلك عن طريق نطوير مفاهيم تخطيط الفراغ الداخلي للمسكن بحيث لا لهابل

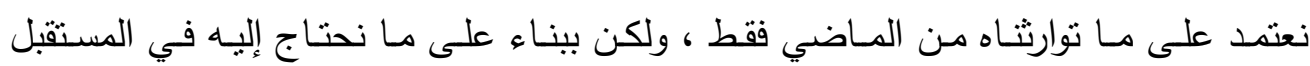
أيضا .

وكذلك نتوقع ظهور أنمـاط من العمارة الداخلية جديدة لم تكن موجودة من قبل ،

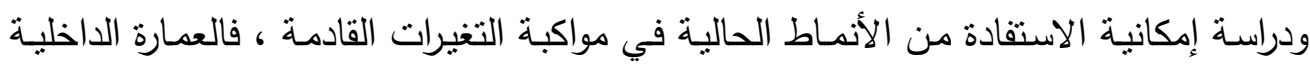

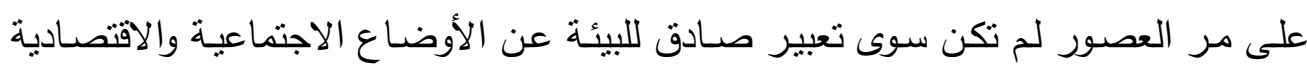

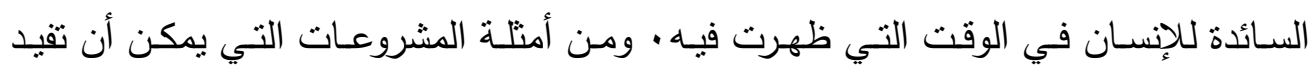

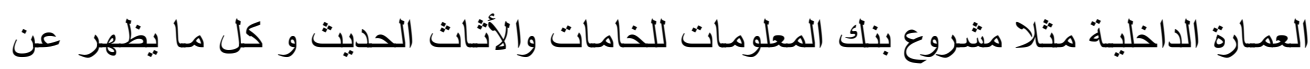
العمارة الداخلية و تربط المجتمعات عن طريق شبكة المعلومـات العالمية والمحلية ، ويمكن من خـلال إعادة استكثـاف الحلول والتخطيط الذي يلائم التغيرات والاحتياجات المستقبلية للمجتمعات في عصر المعلومات بالإضافة إلى أهميته كوسيلة تعليمية وبحثية . 


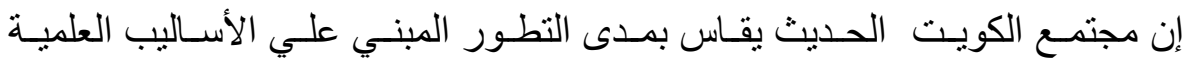

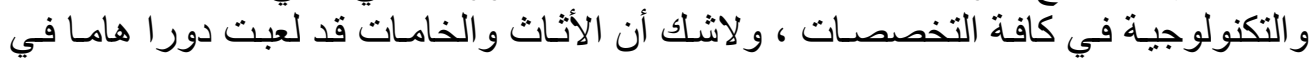

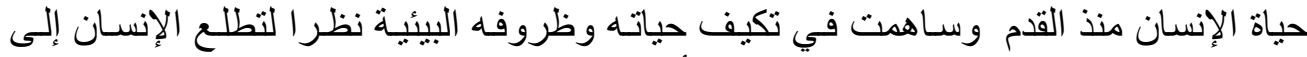

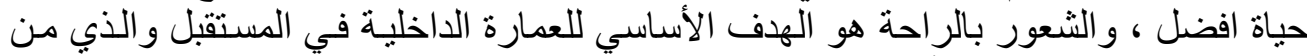

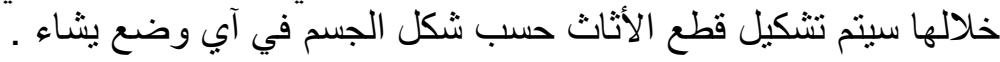
لذلك حان الوقت لكي نتمسك بآلاتي :

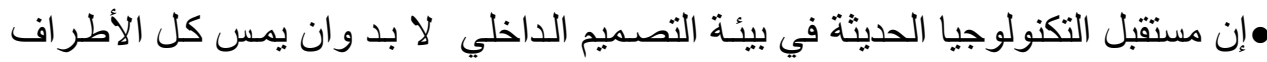

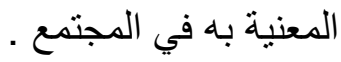
•التصميم الداخلي هي العمل العيع الوحيد المتكامل الذي يمس كل أطر اف المجتمع في السكن

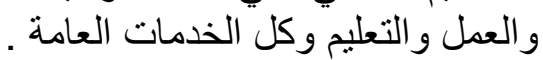

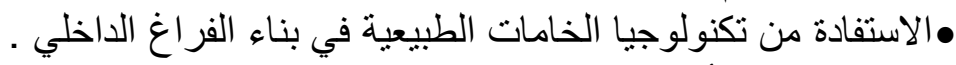

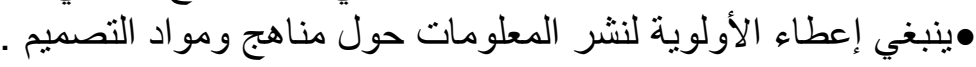

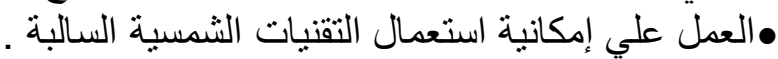

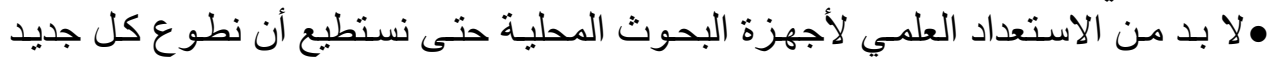

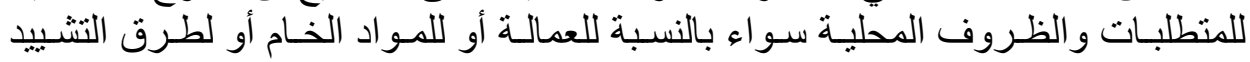

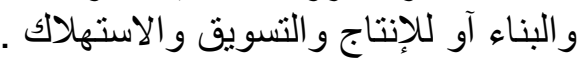

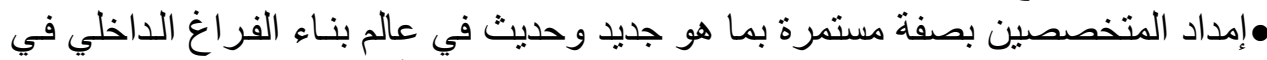

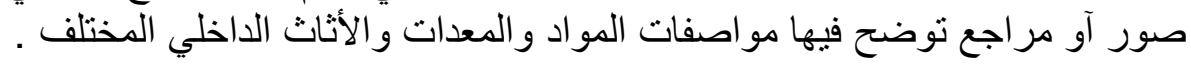

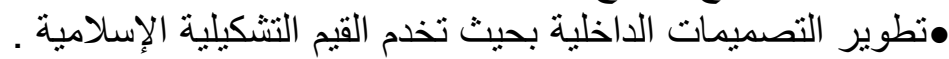

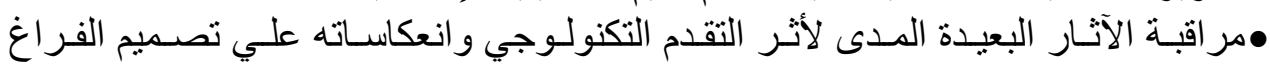

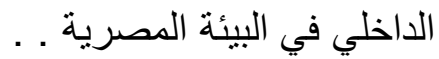


ال. ارنست فيثـر ـ ضـرورة الفن ـ ترجمـة أسـعد حليم ـ الهيئة العامـة للتـأليف و النشـر .

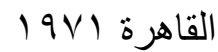

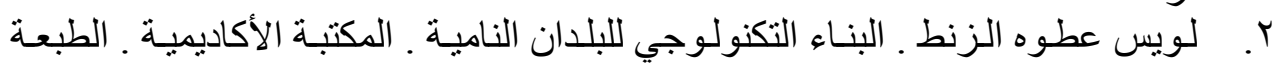

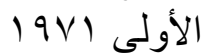

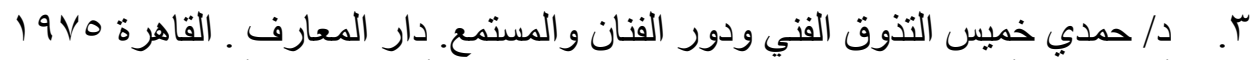

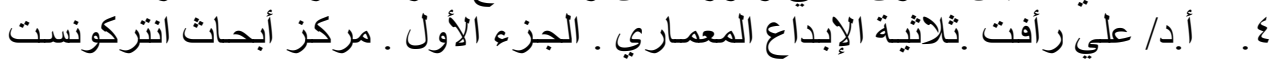
1997

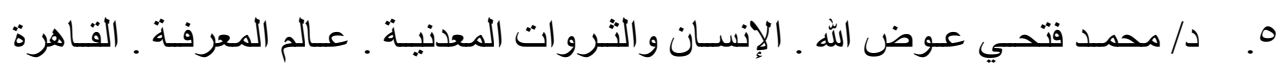
.191 .

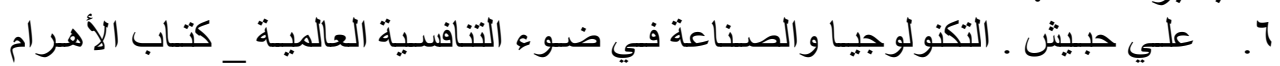

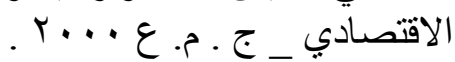

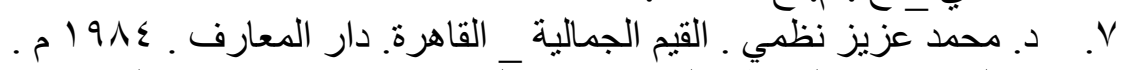

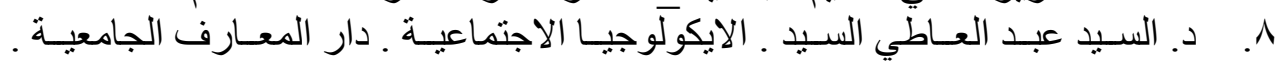

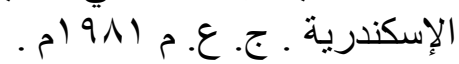

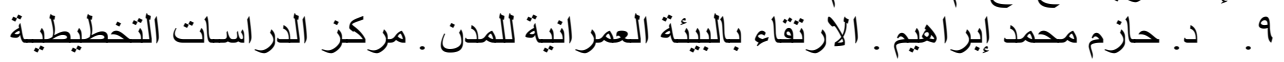

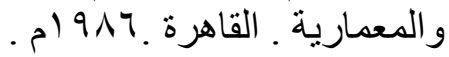
• 1 ـ د. محمد عبد القادر الفقي ـ البيئة ـ مشاكلها وقضاياها وحمايتها من التلوث ـ مكتبة ابن

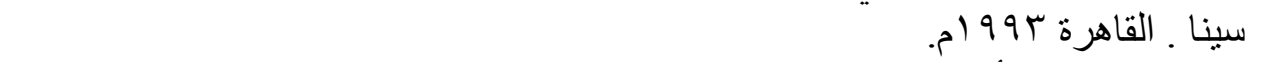

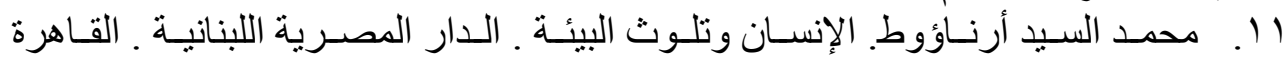
. 1999

-WITELEY NIGEL-DESIGN FOR SOCIETY-REACTION-BOOKSLTD-LONDON-1993

-NORMAN K-BOOTH-BASIC ELEMENTS OF LANDSCAPE ARCHITECURAL DESIGN-SCIENCE PUBLISHING-CO - NEW YORK-U S A - 1983-

-WOODHAM-JONATHAN-TWENIETH-CENTURY DESIGNOXFORD UNIVERITY -New York 1997 
العدد الثالث عشر / المجلد الأول المجلة العلمية بحوث في العلوم و الفنون النوعيه

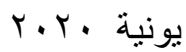

